\title{
O PAPEL DA LOGÍSTICA REVERSA NA GESTÃo AMBIENTAL DA ASSOCIAÇÃO ARPEV.
}

Tais Fernanda de Souza Oliveira, Renato Carlos Camacho Neves

Universidade do Oeste Paulista - UNOESTE, Presidente Prudente, SP. E-mail: taisfernanda.oliveira6@gmail.com

\section{RESUMO}

A logística reversa exerce uma imprescindível função amenizar os impactos ambientais e, consequentemente, beneficiar as divisões socioambientais. O objetivo geral deste artigo foi analisar como a logística reversa, junto com a gestão ambiental, é aplicada a uma associação de recolhimento de embalagens descartáveis de produtos fitossanitários, por meio da cadeia de destinação final pós consumo. 0 método da pesquisa foi através da abordagem qualitativa, com uma pesquisa exploratória, estudo de caso e, como instrumentos de coletas de dados, pesquisa bibliográfica, análise documental, entrevistas e aplicação de um questionário. Por intermédio da aplicação da Logística Reversa em suas operações, baseadas na gestão ambiental, a ARPEV desenvolve um importante papel no exercício das responsabilidades prescritas pela legislação na destinação final de embalagens de agrotóxicos. Concluímos que ARPEV tem utilizado a logística reversa e a gestão ambiental nas suas atividades e processos.

Palavras-chave: Logística Reversa. Gestão Ambiental. Embalagens de Agrotóxicos. Pós Consumo. ARPEV.

\section{THE ROLE OF REVERSE LOGISTICS IN THE ENVIRONMENTAL MANAGEMENT OF ASSOCIATION ARPEV.}

\begin{abstract}
The reverse logistics fulfills an essential function, mitigating the environmental impacts and, consequently, benefiting the socio-environmental divisions. The general objective of this article was to analyze how reverse logistics in conjunction with environmental management is applied to an association of collection of disposable packaging of phytosanitary products, through the postconsumer final destination chain. The research method was based on the qualitative approach, with an exploratory research, case of study, with instruments of data collection, bibliographic research, documentary analysis, interviews and the application of a questionnaire. Through the application of Reverse Logistics in its operations, based on environmental management, ARPEV plays an important role in the exercise of the responsibilities prescribed by the legislation regarding the final destination of agrochemical packaging. We concluded that ARPEV has used the reverse logistics and the environmental management in your activities and processes.
\end{abstract}

Keywords: Reverse Logistics. Environmental management. Packaging of Agrochemicals. Postconsumption. ARPEV. 


\section{INTRODUÇÃO}

Em virtude da globalização mundial, o aumento significativo na demanda nos diversos segmentos de mercado, a procura pela padronização dos produtos e a redução no ciclo de vida dos produtos bem de consumo duráveis e não duráveis e os níveis de produção apresentam crescimento cada vez maior.

Em face do exposto, a logística reversa tem desempenhado um importante papel, pois opera e controla o fluxo e as informações, desde o retorno dos produtos de pós-venda e de pósconsumo, ao ciclo de negócios ou ao ciclo de produção, por meio da cadeia de distribuição reversa, somando e agregando-Ihes valor nas diversas divisões: econômica, ecológica, legal, logística, de imagem social, dentre outras.

Segundo o Instituto Nacional de Processamento de Embalagens Vazias (INPEV), desde 2005 o Brasil é líder mundial na destinação de embalagens vazias de defensivos agrícolas. No país, nove em cada dez embalagens de agrotóxicos são devolvidas pelo produtor rural para serem recicladas ou incineradas. Em 2014, o Brasil retirou 42.646 toneladas desse material, um índice recorde de 94\%. Um conjunto de leis buscou regulamentar sua aplicação, sem, no entanto, dispor sobre a destinação das embalagens pós-consumo. Sem alternativas, o agricultor valia-se de prerrogativas como enterrá-las, queimá-las e até descartá-las em rios ou na própria lavoura, colocando em risco o meio ambiente.

Optou-se em pesquisar a Associação Regional de Recebimento e Prensagem de Embalagens Vazias (ARPEV), localizada na cidade de Paraguaçu Paulista, no Estado de São Paulo, cuja principal ação é o recolhimento de embalagens de produtos fitossanitários ${ }^{1}$ pós-consumo, aplicando a elas destinação final correta, sendo enviadas para reciclagem ou incineração.

0 presente artigo se justifica por contribuir junto à sociedade a preservação do meio ambiente através da destinação final das embalagens descartáveis de produtos fitossanitários, com foco no engajamento de todos os elos da cadeia produtiva agrícola, desde a indústria, os canais de distribuição, os agricultores e as poderes públicos e reconhecendo a importância da conscientização ambiental.

Diante desse contexto, como é aplicada a logística reversa nas atividades desenvolvidas pela ARPEV? E qual a sua contribuição na gestão ambiental?

Acredita-se que por meio da aplicação da Logística Reversa em suas atividades permeadas na gestão ambiental, a ARPEV tem desempenhado um importante papel para o cumprimento das responsabilidades, definidas pela legislação, na destinação final de embalagens descartáveis de produtos fitossanitários.

O objetivo geral deste artigo será analisar como a logística reversa, junto com a gestão ambiental, é aplicada a uma associação de recolhimento de embalagens descartáveis de produtos fitossanitários, por meio da cadeia de destinação final pós- consumo.

\section{METODOLOGIA}

O método é o conjunto das atividades sistemáticas e racionais que, com maior segurança e economia, permite alcançar o objetivo conhecimentos válidos e verdadeiros, traçando o caminho a ser seguido, detectando erros e auxiliando as decisões do cientista, segundo Marconi e Lakatos (2010).

O estudo de caso se caracteriza quando o sujeito que deseja alcançar o conhecimento sobre o seu objeto de estudo se predispõe e vai presenciar no local em que se encontra o fato ou conteúdo que se quer conhecer, com a naturalidade de onde, como e porque acontecem. (MARCONI e LAKATOS, 2010).

\footnotetext{
${ }^{1}$ Fitossanitário: Que serve para combater as pragas ou para aumentar a produtividade agrícola. Relativo à preservação e defesa das plantas ou da flora em geral. 
As pesquisas exploratórias são compreendidas como investigações de pesquisa empírica cujo objetivo é a formulação de questões ou de um problema, com tripla finalidade: desenvolver hipóteses, aumentar a familiaridade do pesquisador com um ambiente, fato ou fenômeno para a realização de uma pesquisa futura mais precisa ou modificar e clarificar conceitos (MARCONI e LAKATOS, 2003, p. 188).

Os instrumentos de coletas de dados utilizados no referido artigo serão a pesquisa bibliográfica, a análise documental e a aplicação de entrevistas com a utilização de questionário.

\section{FUNDAMENTAÇÃO TEÓRICA}

\section{LOGÍSTICA}

Tradicionalmente, as empresas incluíam a simples entrada de matérias-primas ou o fluxo de saída de produtos acabados em sua definição de logística. Hoje, no entanto, essa definição expandiu-se e inclui todas as formas de movimentos de produtos e informações.

De acordo com Leite e Dornier (2003), a logística é a gestão de fluxos entre funções de negócio. A definição atual de logística engloba maior amplitude de fluxos do que no passado. Com base nas abordagens conceituais, logística não representa apenas uma fonte de vantagem competitiva, ela representa a razão de ser da empresa, algo mais do que apenas movimentação de produtos/serviços. É a integração entre áreas da empresa para reduzir custos, melhorar o fluxo de informação e agregar valor ao produto/serviço.

A logística é dividida em quatro tipos, nos quais a logística reversa vem sendo mencionada com frequência no meio empresarial e educacional, tendo o papel sustentável na empresa, com o reuso e reciclagem de produtos e redução de insumos e poluição ao meio ambiente.

\section{LOGÍSTICA REVERSA}

Nitidamente, quando se fala que o produto deve retornar à sua origem, não se intenciona dizer que ele deve ser devolvido precisamente ao ponto em que foi fabricado, mas, sim, voltar para a empresa que o produziu. A empresa, por sua vez, dará o destino que lhe for mais propício: pode ser recuperá-lo, reciclá-lo, vendê-lo para outra empresa ou, até mesmo, jogá-lo no lixo. Logística reversa diz respeito ao fluxo de materiais que voltam à empresa por algum motivo tais como: devolução de produtos com defeitos, retorno de embalagens ou retorno de produtos e/ou materiais para atender à legislação. A atividade principal é a coleta dos produtos a serem recuperados e a sua distribuição após reprocessamento.

$\mathrm{Na}$ visão de Leite (2003), a logística reversa é a área da logística empresarial que visa equacionar os aspectos logísticos do retorno dos bens ao ciclo produtivo ou de negócios, por intermédio da multiplicidade de canais de distribuição reversos de pós-venda e de pós-consumo, agregando-Ihes valor econômico, ecológico e legal.

É iminente o perigo quando do retorno de produtos altamente nocivos ao meio ambiente, como as embalagens de agrotóxicos. A atividade principal da logística reversa é a coleta dos produtos a serem recuperados e a sua distribuição após o reprocessamento. A mesma atua com duas divisões, pós-consumo e pós-venda.

\section{GESTÃO AMBIENTAL}

A Gestão Ambiental começou a ser notada em meados da década de 60, quando começou o processo de industrialização. "A década de 60 viu surgirem os primeiros movimentos ambientalistas motivados pela contaminação das águas e do ar nos países industrializados" (VALLE, 1992, p. 2).

A conservação com o meio ambiente tem sido um assunto constantemente debatido pela comunidade. Diante disso, cresceu o número de pessoas no âmbito mundial que assumiram uma postura diferente e passaram a empenhar esforços para a preservação do meio ambiente. Devido 
à degradação gerada, as empresas tiveram sua imagem prejudicada diante do ambiente mercadológico. Diante do exposto, o conceito de gestão ambiental passou a ser mais divulgado, alavancando a sua importância e assumindo um papel de ferramenta estratégica praticada pelas organizações empresariais.

A gestão ambiental apresenta três pilares: econômico, social e ambiental, conhecido como Triple Bottom Line. Segundo Dias (2011), o Triple Bottom Line é também conhecido como os 3 Ps (People, Planet and Profit, ou em português, Pessoas, Planeta e Lucro). No Brasil, é conhecido como "tripé da sustentabilidade", um conceito que tanto pode ser aplicado de maneira macro, para um país ou o próprio planeta, como micro, numa residência, numa empresa, numa escola ou numa pequena vila.

\section{CARACTERIZAÇÃO DA ORGANIZAÇÃO}

A unidade Central de Recebimento de Embalagens Vazias, denominada Associação Regional de Recebimento e Prensagem de Embalagens Vazias (ARPEV), está localizada à Rodovia SP 284, Km 481,5, na cidade de Paraguaçu Paulista, no Estado de São Paulo com funcionamento desde março de 2000.

A missão da ARPEV é contribuir para a preservação do meio ambiente com a gestão voltada para a destinação final correta das embalagens vazias de agrotóxicos e resíduos sólidos da agropecuária.

A ARPEV tem como atividade principal receber as embalagens dos postos de recebimento de toda a região. Atualmente os postos estão localizados nas cidades de Palmital, Marília, Garça, Assis, Pedrinhas Paulista e Cândido Mota, atendendo aproximadamente 80 municípios. Após o recebimento e inspeção, os postos têm a tarefa de transportar até à Central, no Município de Paraguaçu Paulista.

Durante o recebimento das embalagens na Central, é realizada uma inspeção verificando se as embalagens passaram pelo processo de tríplice lavagem, ou seja, se foram lavadas 3 vezes, para que assim elimine possíveis resíduos dos defensivos. Após a inspeção, é realizada uma separação por tipo dos materiais. As tampas são separadas por cor e, as embalagens são prensadas, armazenadas e, futuramente, enviadas para destinação final e correta, sendo reciclagem ou incineração. O transporte e a destinação final são administrados pelo Instituo Nacional de Processamento de Embalagens Vazias (INPEV), que é o representante dos fabricantes.

Em visita técnica no mês de março 2018 ao local de funcionamento da ARPEV, in loco ficou constatado que os procedimentos obrigatórios e legais previstos na legislação quanto ao uso dos equipamentos de proteção individual (EPIs) são adotados pela unidade.

\section{INSTRUMENTOS DE COLETA DE DADOS}

Os instrumentos de coletas de dados utilizados no referido artigo foram a pesquisa bibliográfica, a análise documental e a aplicação de entrevistas com a utilização de questionário.

Instrumentos de pesquisa são os meios através dos quais se aplicam as técnicas selecionadas. Se uma pesquisa vai fundamentar a coleta de dados nas entrevistas, tornase necessário pesquisar o assunto, para depois elaborar o roteiro ou formulário. Evidentemente, os instrumentos de uma pesquisa são exclusivos dela, pois atendem às necessidades daquele caso particular. A cada pesquisa que se pretende realizar procedese à construção dos instrumentos adequados.

(ANDRADE, 2009, p. 132/133).

A pesquisa bibliográfica tem o objetivo de unir as informações e dados que servirão de base para a construção do artigo a partir de determinado tema. Além de pautar um histórico sobre o tema escolhido, ajuda a apontar contradições de variados autores. 
A pesquisa documental representa uma rica fonte de dados verídicos sobre a Associação, buscando uma apuração de materiais que ainda não foram observados de forma analítica, buscando novas interpretações, ou mesmo interpretações complementares para a elaboração do artigo.

Para Selltiz, Wrightsman e Cook, (1987), a importância das entrevistas como instrumento de coleta de dados está ligada ao fato de que, por meio do relato verbal, apreendem-se o nível de conhecimento, as crenças, as motivações, as expectativas, os planos e as atitudes das pessoas. Portanto, o objetivo é em alto grau exploratório e não segue um roteiro prefixado, ou, então, quando tiver um roteiro, o mesmo pode ser alterado.

\section{ANÁLISE DE DADOS}

A consulta documental foi a fonte de informações que utilizamos para colher registros da Associação, sob a forma de documentos, fichas e relatórios, etc. O uso de registros e documentos já disponíveis reduziu o tempo e a elaboração de um escopo para a entrevista e aplicação do questionário.

A aplicação da entrevista foi a fim de obtermos informações a respeito da associação ARPEV e de suas atividades, mediante uma conversação de natureza profissional. Com a aplicação da entrevista possibilitou-se uma maior flexibilidade e propiciou a disposição para repetir ou esclarecer possíveis dúvidas, elaborar perguntas de maneira diferente e fazer a aplicação de um formulário, assim recolhendo as informações necessárias para o desenvolvimento do presente artigo.

\section{RESULTADOS}

O presente artigo expresso a relevância da logística reversa na gestão ambiental inserida nas atividades e ações da ARPEV, no tocante ao recolhimento de embalagens pós-uso de defensivos agrícolas. Pode ser constatado que o objetivo principal da Associação não é apenas o lucro, mas também a contribuição para a sustentabilidade ambiental.

É possível enxergar o quão é importante os canais da logística reversa, com foco no que se refere ao destino correto das embalagens vazias de agrotóxicos, executadas habitualmente por agricultores, que é o consumidor principal destes produtos.

Entende-se que com a limitação e a escassez das fontes de recursos naturais e o aumento na demanda de consumo da população mundial, tornam-se cada vez mais necessários esforços e ações para o reaproveitamento de quaisquer tipos de matéria, fazendo com que retornem à cadeia produtiva, possibilitando a fabricação de outros bens e produtos para uso e consumo, contribuindo para um mundo mais sustentável e garantindo para as próximas gerações os recursos necessários para a sobrevivência, ações essas pautadas no tripé da sustentabilidade, sendo este econômico, ambiental e social.

\section{CONCLUSÃO}

Este presente artigo buscou de modo direto contribuir para a disseminação da informação pertinente à forma correta de descarte de embalagens de defensivos agrícolas, através da aplicação e utilização da logística reversa pós-consumo atrelada à gestão ambiental, em razão de estarmos localizados no Oeste Paulista, interior do estado de São Paulo, onde quase a totalidade dos munícipios tem como base a agricultura para seu desenvolvimento econômico e, por consequência, temos um volume expressivo de embalagens vazias.

A ARPEV não impõe nenhuma barreira em relação à quantidade de embalagens a serem entregues, independente do porte da organização/agricultor é possível efetuar a destinação correta. 
Ao longo do processo de desenvolvimento da pesquisa nos deparamos com alguns fatores os quais dificultaram o desenvolvimento do objeto de estudo. Dentre eles podemos citar a indisponibilidade de tempo por parte do gestor responsável pela ARPEV, tempo escasso dos pesquisadores para visitas in loco à Associação para coleta de dados e o reduzido número de livros explanando diretamente o assunto de logística reversa e sua aplicabilidade no território nacional.

\section{REFERÊNCIAS}

DIAS, R. Gestão ambiental: uma responsabilidade social e sustentabilidade. 2. ed. São Paulo: Atlas, 2011.

Instituto Nacional de Processamento de embalagens Vazias (INPEV). Sobre nós. Disponível em: <http://www.inpev.org.br/inpev/index>. Acesso em: 20 de ago. 2017.

LAKATOS, E. M.; MARCONI, M. A. Fundamentos da metodologia científica. 5. ed. São Paulo: Atlas, 2003.

LAKATOS, E. M.; MARCONI, M. A. Fundamentos da metodologia científica. 7. ed. São Paulo: Atlas, 2010.

VALLE, C.E. Como se preparar para as normas ISO 14000. 2o ed. São Paulo: Pioneira, 1995. 